\title{
Development of laser rifle trainer with full shot imitation
}

\author{
Ramutis Bansevicius, Algimantas Fedaravicius*, Vytautas Ostasevicius and Minvydas Ragulskis \\ Kaunas University of Technology, Kaunas, Lithuania
}

Received 12 January 2003

Accepted 26 September 2003

\begin{abstract}
Laser trainers are effective tools for shot and sportsmen training. However, the majority of trainers have neither realistic recoil nor sound imitation systems. The objective of the development of laser rifle trainer with full shot imitation was to investigate and simulate the recoil of combat weapons under single and serial shooting regimes so that the training weapons could simulate complete recoil and sound imitation.

Theoretical and experimental investigations lead to the development of shot training systems which were successfully implemented in Lithuanian Army combat training facilities. The laser trainers are also equipped with interactive software interface which does not only control and register the process of shooting but also can reproduce the whole set of statistical data, including psychological impact on the rifleman and detection of his training problems. The incorporation of multimedia advances the system up to interactive laser shot trainer in virtual combat reality.
\end{abstract}

\section{Introduction}

Laser trainers are effectively used for shot and sportsmen training. However, the majority of trainers have neither a real recoil nor sound imitation systems. The objective of this work is to investigate the recoil of combat weapons under single and serial shooting regimes so that training weapons could be developed with a camplete recoil imitation.

It is clear that the training equipment of the riflemen must reproduce the process of single shots and shot serial as precisely as possible. Thus the efficiency of the training equipment is determined by the maximum reproduction of physical and psychological influence characteristics on a riflemen of the real fighting guns (shot and shot serial, recoil and sound, imitation of real fighting situation etc.) and rendering of additional information to the shooting instructor and the rifleman through the additional informational systems (e.g. po-

*Corresponding author: A. Fedaravicius, Kestucio 27, Kaunas University of Technology, Kaunas, Lithuania. Tel.: +370 7 324140; Fax: +370 7 324140; E-mail: minvydas.ragulskis@fmf.ktu.Lt. sition of the sight at the moment of a shot, the process of trigger pressing, the correctness of butt pressing to the rifleman's shoulder, the trajectory of gun targeting etc.).

\section{Investigation of dynamic properties of combat arms (PISTOL TT AND ASSAULT CARABINE AK-47S)}

Main technical problems arising in the process the design of laser rifle trainer could be enumerated as follows:

- simulation of realistic virtual combat environment;

- simulation of realistic shot noise;

- simulation of realistic recoil forces.

If the first two tasks could be solved using computer technology, the simulation of recoil forces required the development of mechanical recoil simulation. The requirements for the simulator could be presented as follows:

- simulation of single shot and serial shot models; 


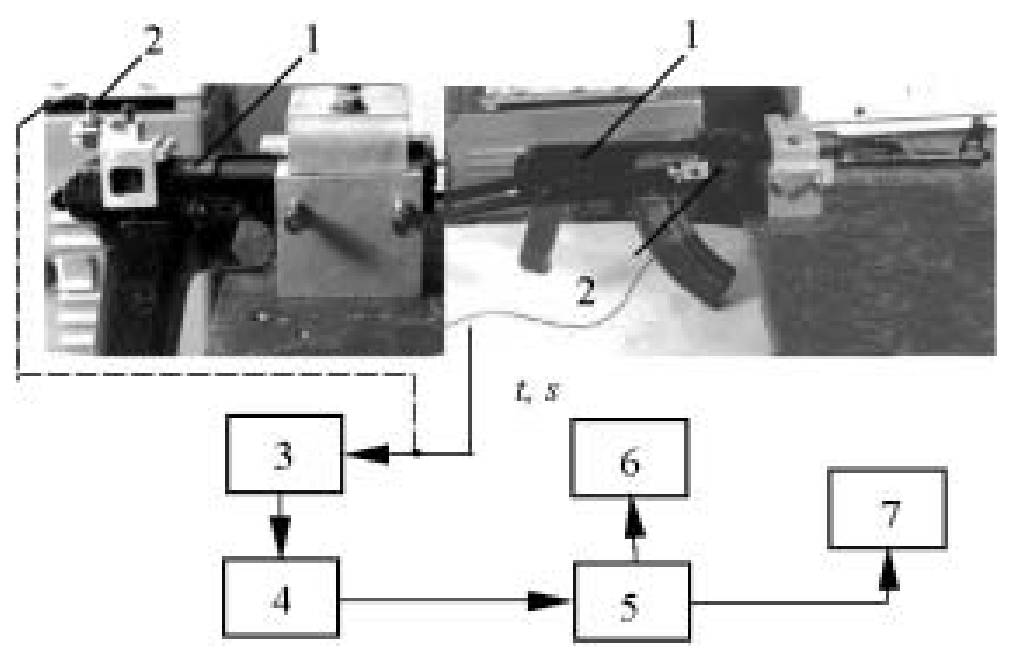

Fig. 1. Research scheme of the lock dynamics during single shots and serials: 1 - gun (pistol or storm carabine), 2 - piezoelectric sensor KD 17 , 3 - vibration meter RFT, 4 - converter - code - analog, 5 - PC, 6 - monitor, 7 - printer.
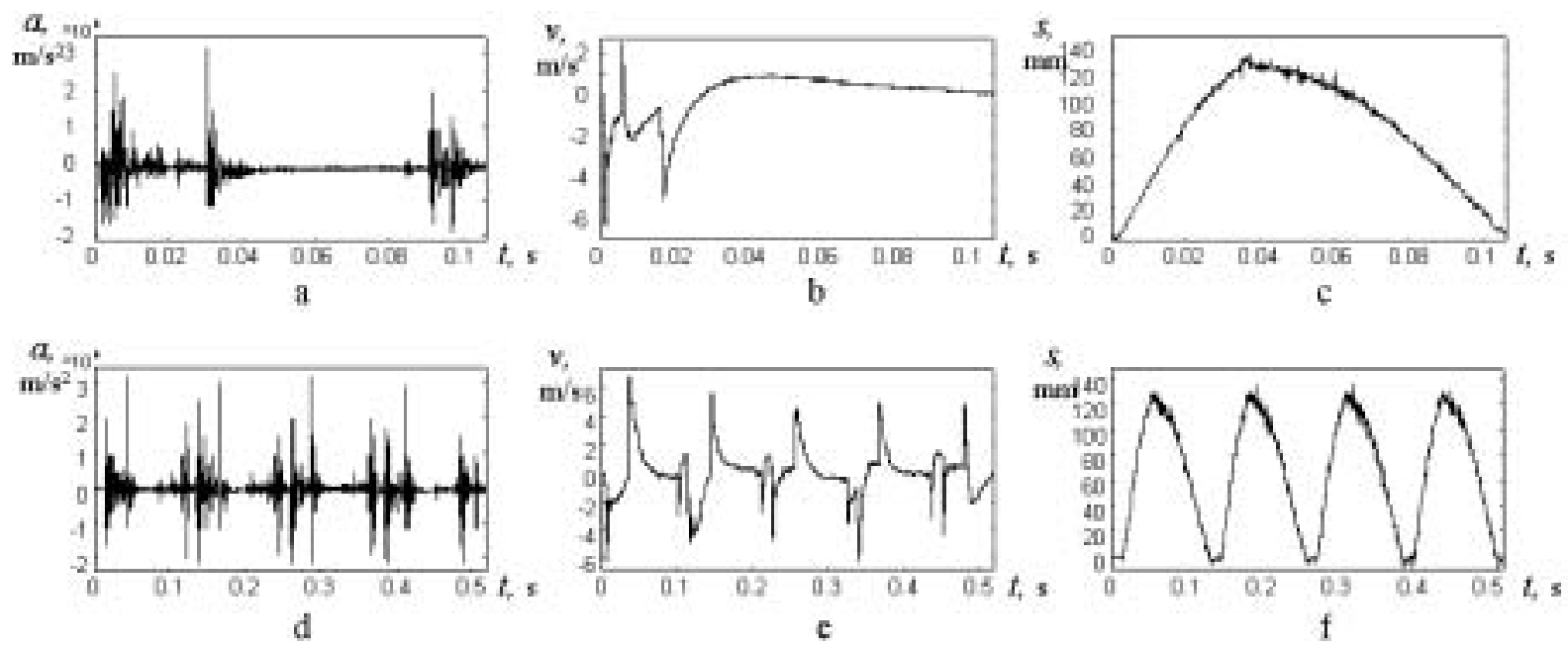

Fig. 2. Experimental characteristics of dynamic parameters of the lock movement of AK-47S gun: acceleration (a), velocity (b), displacement (c) of a storm carabine in single shot mode, and acceleration (d), velocity (e), displacement (f) in serial shot mode.

- simulation of realistic forces, energies, frequency spectrum, signal time functions;

- ability to operate at relatively high frequencies (up to $10 \mathrm{~Hz}$ ) in serial shot mode;

- the recoil simulation must minimally modify the structure of the rifle, preferably the mechanical recoil simulator to be located in the butt-stock of the rifle.

Thus the parameters of the gun dynamics during the shooting process must be measured on specific rifles and serve as the reference information for the synthesis of the recoil simulation mechanisms.
Figure 1 presents the experimental measurement stand where the acceleration, velocity and displacement are measured on the original combat rifles during the shooting process.

The powder gas pressure inside gun mechanism can be approximated by following function [2]:

$$
p(t)=p_{v g} e^{-t / b}
$$

where $p_{v g}$ is powder gas pressure at the barrel thin-end, $b$ - factor evaluating powder gas mass impact on barrel walls, initial bullet velocity, channel cross-section, powder load mass.

The maximum value of gas pressure can be calculated from formula [2]: 


$$
p_{\max } l_{v k}=\frac{E_{0}}{\eta_{p} n_{s} d^{2}},
$$

where $E_{0}$ - cartridge energy, $\varphi$ - bullet mass fictitiousness factor, pmax - maximum powder gas pressure, $l_{v k}$ - barrel channel length, $\eta_{p}$ - factor of powder gas pressure function mean $\left(\eta_{p}=0,5 \div 0,6\right), n_{s}-$ efficiency factor $\left(n_{s} \approx 0,82\right), d-$ gun calibre. Time required for the bullet to leave the barrel channel can be approximated as:

$$
\tau=\frac{5 l_{v k}}{v_{0}},
$$

where $v_{0}$ - initial bullet velocity.

Gun recoil velocity and energy are very important parameters for the design of the recoil simulator. The relationship between the gun and bullet weight takes the form:

$$
\frac{Q}{q}=\frac{v_{o}}{v},
$$

where $Q$ is gun weight, $q$ - bullet weight, $v$ - recoil velocity, $v_{0}$ - bullet initial velocity.

The recoil energy of riflemen guns can be found from:

$$
E_{a t}=\frac{Q \cdot c^{2}}{2 g},
$$

where $g$-acceleration of gravity.

Figure 2 represents acceleration, velocity and displacement time signals measured for AK-47S automatic gun in single shot and serial shot modes.

Data from the measurements and relationships in Eq. (5) lead to the expression of recoil velocities and energies for different types of guns (Table 1).

\section{Dynamical synthesis of mechanism of gun recoil imitation}

One of the main requirements for gun recoil imitation system is its ability to reproduce the pressure pulses of a real gun as accurately as possible. The accuracy of simulation involves not only matching of the recoil energies of the simulator and a real gun but also the time duration as well as frequency characteristics of pressure signals in single shot and shot serial modes of operation. Such task is non trivial first of all due to the available space and weight limitations - the recoil imitation mechanism can not alter the weight nor the location of the gravity center of the rifle. On the other hand, the reality of imitation can not be lost in serial shot mode, - what again is a difficult requirement due to

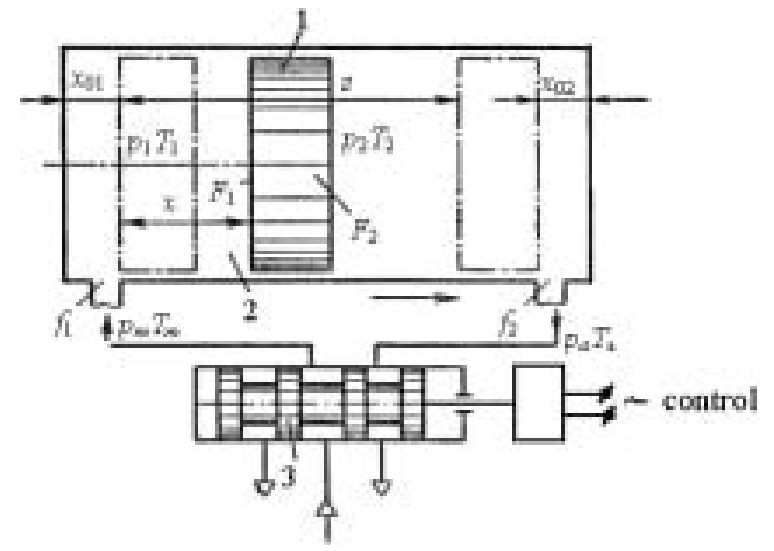

Fig. 3. The scheme of two-way operation pneumatic drive: 1-piston, 2-cylinder, 3- electro-magnetic impulse valve (air distributor).

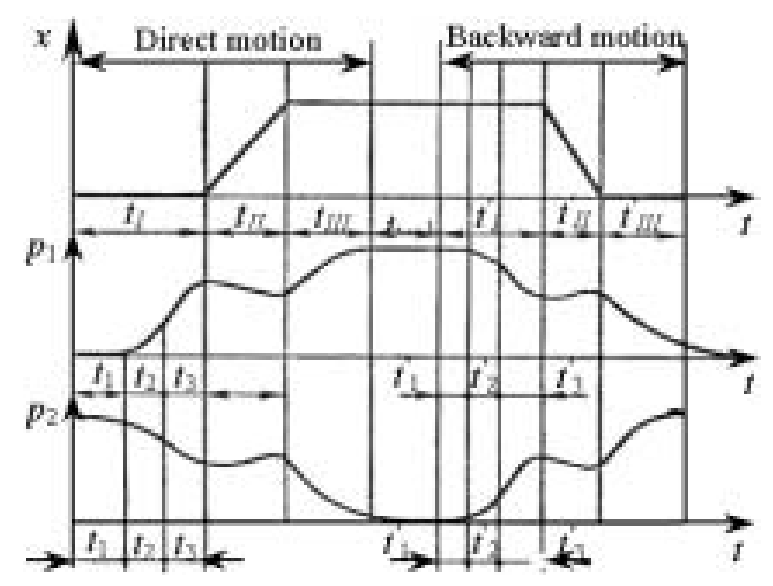

Fig. 4. Cyclogram of the pneumatic drive.

relatively high shot frequency (about $10 \mathrm{~Hz}$ for AK-47 storm carbine). It can be mentioned that analogous rifle simulators [6,7] do not perform realistic recoil imitation first of all due to the fact that the recoil pulse energy is much lower than of a real gun.

The gun recoil imitation was based on the application of pneumatic drive for shock simulation [2,4,5]. Anyway, the synthesis of recoil imitation mechanism was far from being trivial due to the up-mentioned restrictions.

Taking into consideration technical-maintenance and weight-size characteristics of AK-47 storm carbine, the acceptable range of the parameters of the pneumatic drive was limited to the values presented in Table 2.

The pneumatic drive's direct motion time $T_{d . m}$. comprises following terms:

$$
T_{d . m .}=t_{I}+t_{I I}+t_{I I I},
$$




\begin{tabular}{ccccc}
\multicolumn{5}{c}{ Table 1 } \\
\hline Gun type & Gun weight kg & Bullet weight g & Recoil velocity m/s & Recoil energy J \\
\hline AK-47S & 3.50 & 3.4 & 1.30 & 2.94 \\
PM & 0.81 & 6.1 & 5.87 & 13.73 \\
ČZ & 1.12 & 8.0 & 6.90 & 26.49 \\
COLT & 1.25 & 15.2 & 7.08 & 31.39 \\
\hline
\end{tabular}

Table 2

\begin{tabular}{|c|c|c|c|c|c|c|c|c|c|c|c|}
\hline $\mathrm{D}_{1}, \mathrm{~m}$ & $\mathrm{~m}, \mathrm{~kg}$ & $\mathrm{~s}, \mathrm{~m}$ & $l_{1}, \mathrm{~m}$ & $l_{2}, \mathrm{~m}$ & $d_{1}, \mathrm{~m}$ & $d_{2}, \mathrm{~m}$ & $\mathrm{P}, \mathrm{N}$ & $p_{m}$, atm & $\mu_{1}$ & $\mu_{2}$ & $t_{1}, \mathrm{~s}$ \\
\hline $0.03 \div 0.05$ & $0.3 \div 0.5$ & $0.05 \div 0.12$ & $1.0 \div 1.5$ & $1.0 \div 1.5$ & $0.006 \div 0.012$ & $0.006 \div 0.012$ & 15 & $5 \div 12$ & 0.2 & 0.4 & $0.011 \div 0.025$ \\
\hline
\end{tabular}

where $t_{I}$ - preparative period, $t_{I I}$ - time of change of piston working motion, $t_{I I I}-$ final period.

The preparative period consists of the following time intervals:

$$
t_{I}=t_{1}+t_{2}+t_{3}
$$

where $t_{1}=11-25 \mathrm{~ms}$ - time the air distributor starts operating; $t_{2}=l / a$ - time required for the air pressure wave to spread from the distributor to the piston ( $l$ is length of air feeding tube); $a$ - velocity of sound in the air $(a=341 \mathrm{~m} / \mathrm{s}$ at $T=290 \mathrm{~K}(170 \mathrm{C})) ; t_{3}$ - time required to fill the working chamber with compressed air.

The piston motion period starts after the preparative period of the drive. The piston motion can be described by the formula:

$$
m \ddot{x}=p_{1} F_{1}-p_{2} F_{2}-p,
$$

and the equations describing the pressure change in the working and outlet chambers respectively are:

$$
\begin{aligned}
\frac{d p_{1}}{d t}= & \frac{k f_{1}^{e} K p_{m} \sqrt{R T_{m}}}{F_{1}\left(x_{01}+x\right)} \varphi\left(\sigma_{1}\right) \\
& -\frac{k p_{1}}{\left(x_{01}+x\right)} \cdot \frac{d x}{d t} \\
\frac{d p_{2}}{d t}= & -\frac{k f_{2}^{e} K p_{2}^{(3 k-1) / 2 k} \sqrt{R T_{m}}}{F_{2}\left(s+x_{02}-x\right) p_{m}^{(k-1) / 2 k}} \varphi\left(\frac{\sigma_{a}}{\sigma_{2}}\right) \\
& +\frac{k p_{2}}{s+x_{02}-x} \cdot \frac{d x}{d t}
\end{aligned}
$$

where $m$ - piston mass; $p_{1}, p_{2}$ - air pressures in the working and outlet chambers; $F_{1}, F_{2}$ - the areas of piston ends on the sides of the working and outlet chambers; $P$ - the friction force.

The time of the final period may be determined according to the same formulas taking into consideration different volumes of both chambers. The pressure increase time in the working chamber can be determined in accordance to the following formula:

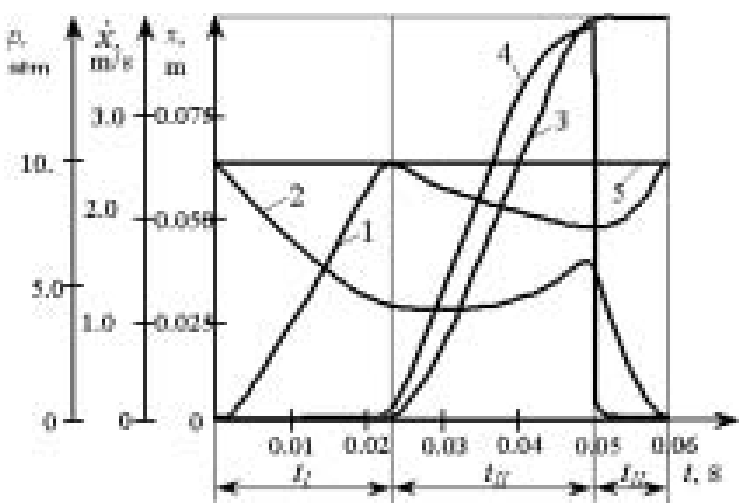

Fig. 5. Diagrams of direct motion of the pneumatic drive: 1 pressure in the working chamber; 2 - pressure in the outlet chamber; 3 - piston shift; 4 - piston velocity; 5 - pressure in the main tube.

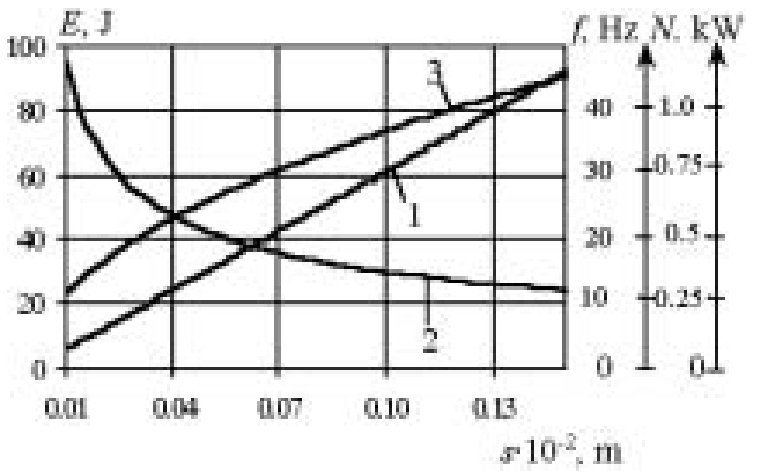

Fig. 6. The relationship between : 1 - impact energy, 2 - frequency, 3 - impact power and the piston displacement (piston mass $m=0.5 \mathrm{~kg}$, piston diameter $D=4 \cdot 10^{-2} \mathrm{~m}$, air pressure in the main tube $p_{m}=10 \mathrm{~atm}$ ).

$$
\begin{gathered}
t_{I I I}=\frac{3.62 \cdot 10^{3}\left(V_{0}+F_{1} s\right)}{f^{e}} \\
{\left[\Psi_{1}\left(\sigma_{2}\right)-\Psi_{1}\left(\sigma_{1}\right)\right]}
\end{gathered}
$$

The results of analysis of the direct motion of the pneumatic drive (pressures in the working and outlet chambers, piston shift and velocity in direct motion) are presented in Fig. 5. 

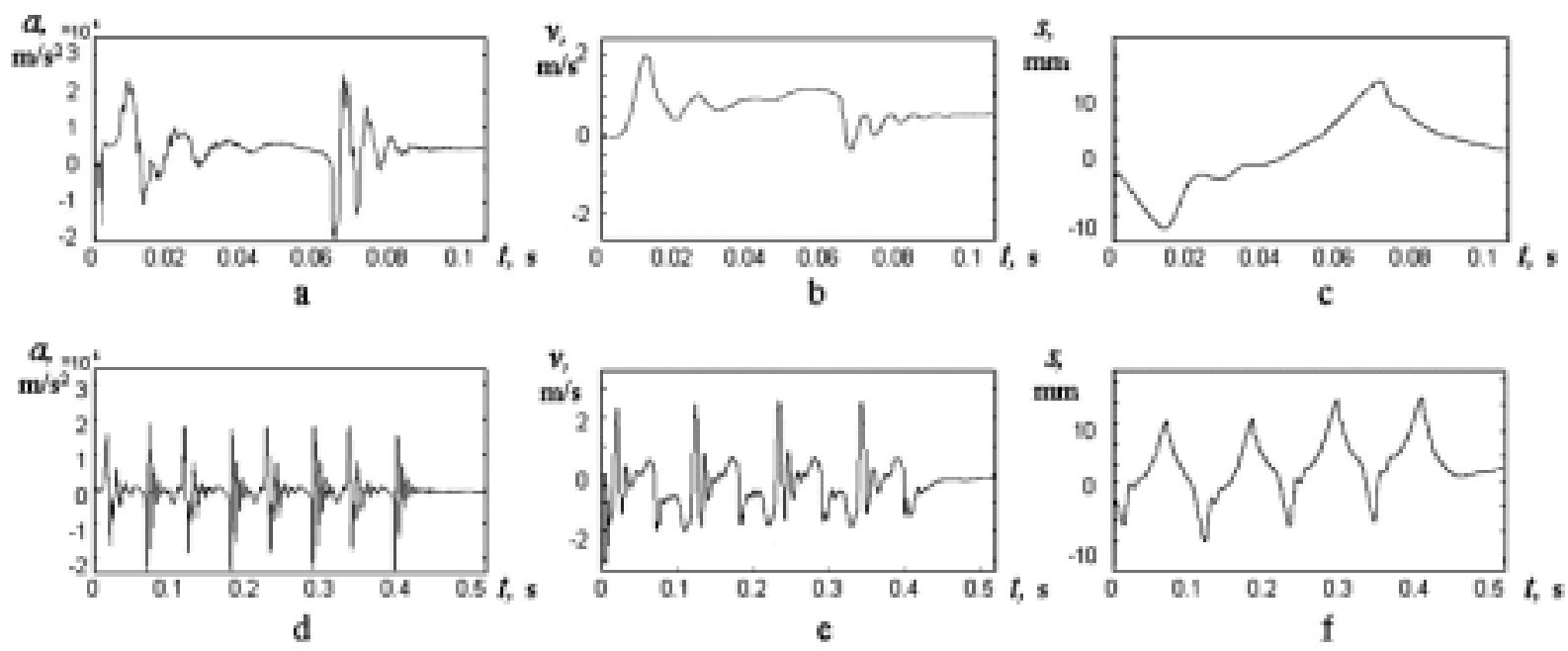

Fig. 7. Experimental characteristics of dynamic parameters of the butt-stock movement of AK-47S training gun: acceleration (a), velocity (b), displacement (c) in single shot mode, And acceleration (d), velocity (e), displacement (f) in serial shot mode.

The obtained results indicate that the synthesised drive differs from the traditional reverse pneumatic drives by such phenomena that the times of the preparative period and piston motion are practically identical, i.e. $t_{I} \approx t_{I I}$, meanwhile in traditional reverse drives $t_{I}<<t_{I I}$. However, diagrams in Fig. 5 show that the piston reaches the value of the set velocity within the period $t_{I I}$. This indicates that under the given parameters of the pneumatic drive, the piston performs full motion cycle and operates in normal regime.

Naturally, the most important characteristic of the synthesised pneumatic drive for the described application is the shock energy of the impact. Another important characteristic is the frequency of repeatability. The pneumatic drive must in the best possible way simulate the shot recoil parameters of a real gun.

The impact energy E can be determined evaluating the final speed of the piston according to the following formula [5]:

$$
E=k_{1} p_{m} F s
$$

where $k_{1}$ - energy loss coefficient which evaluates the degree of air filling in the pneumatic cylinder (under optimum regime $\left.k_{1}=0.5\right) ; p_{m}$ - air pressure in the main tube; $F$ - area of the piston's cross-section; $s-$ displacement of the piston.

Other parameters such as the frequency of shock repeatability $f$ and the power of impact $N$ can be determined according to the corresponding formulas:

$$
f=\frac{k_{2}}{1+\gamma} \sqrt{\frac{p_{m} F}{m s}}
$$

$$
N=0.2 \cdot 10^{3} f s
$$

where $m$-piston mass; $v$ - the set piston velocity; $k_{2}-$ coefficient of piston work reduction due to mechanical losses (for blow pneumatic mechanisms $k_{2}=0.75$ ); $\gamma$ - ratio of direct and reverse piston motions (in our case $\gamma \approx 1.5)$.

Figure 6 represents the determined relationships between the blow energy, power, frequency and the parameters of the system.

\section{Optimisation of the parameters of the system}

The final stage of the design of the gun recoil imitator required the optimisation of the parameters of the system. As mentioned earlier, the basic criteria of the pneumatic drive of rifle recoil imitation is the energy of the impact which in its term is predetermined by many technical-maintenance and weight-size parameters of the pneumatic drive. The basic criteria selected for optimization: E - energy of the impact (because this parameter is a generally accepted characteristic of all riflemen's guns), and 1/KDN minimum absolute deflection from the set shooting speed capacity, where

$$
K D N=\frac{1}{|10-f|}
$$

The following parameters were selected for the optimization of the pneumatic drive of rifle recoil imitation: $m$ - piston mass; $f$ - working frequency of the piston; $p_{m}$-air pressure in the main tube; $D$ - piston diameter; $s-$ working motion of the piston; $l_{1}=l_{2}-$ lengths 


\begin{tabular}{|c|c|c|c|c|}
\hline \multicolumn{5}{|c|}{$\begin{array}{c}\text { OPTIMIZATION ACCORDING TO LP SEARCH, } \\
\text { CRITERIA } 2 \\
\text { PARAMETERS } 4 \\
600 \text { TESTS FROM } 1 \text { TO } 600 \\
\end{array}$} \\
\hline $\inf \mathrm{X} 1=$ & $0.50000 \mathrm{E}+01$ & $\sup X 1=$ & $0.10000 \mathrm{e}+02$ & $(\mathrm{pm})$ \\
\hline $\inf \times 2=$ & $0.30000 \mathrm{E}+00$ & $\sup \times 2=$ & $0.50000 \mathrm{e}+00$ & $(\mathrm{~m})$ \\
\hline $\inf \times 3=$ & $0.50000 \mathrm{E}-01$ & $\sup X 3=$ & $0.12000 \mathrm{e}+00$ & (s) \\
\hline $\inf \times 4=$ & $0.30000 \mathrm{E}+01$ & $\sup \times 4=$ & $0.50000 \mathrm{e}+01$ & (D) \\
\hline \multicolumn{5}{|c|}{ TABLE OF SORTED OUT CRITERIA } \\
\hline $\mathrm{E}$ & & Test No. & KDN & test No. \\
\hline 114.6595 & & 383 & 0.2225 & 448 \\
\hline 114.0690 & & 511 & 0.2217 & 192 \\
\hline 114.0064 & & 255 & 0.2209 & 480 \\
\hline 113.8801 & & 127 & 0.2205 & 512 \\
\hline 113.8165 & & 447 & 0.2202 & 224 \\
\hline 113.7524 & & 191 & 0.2198 & 576 \\
\hline 112.9780 & & 319 & 0.2193 & 464 \\
\hline 112.5447 & & 575 & 0.2190 & 544 \\
\hline 112.2074 & & 63 & 0.2186 & 208 \\
\hline 111.3150 & & 351 & 0.2185 & 64 \\
\hline 110.7391 & & 479 & 0.2181 & 256 \\
\hline 110.6775 & & 223 & 0.2177 & 32 \\
\hline 110.5530 & & 95 & 0.2177 & 496 \\
\hline
\end{tabular}

\begin{tabular}{ccccccccc}
\multicolumn{10}{c}{ Table 4} \\
\hline$D_{1}, \mathrm{~m}$ & $\mathrm{~m}, \mathrm{~kg}$ & $\mathrm{~s}, \mathrm{~m}$ & $l_{1}, \mathrm{~m}$ & $l_{2}, \mathrm{~m}$ & $d_{1}, \mathrm{~m}$ & $d_{2}, \mathrm{~m}$ & $p_{m}$, atm & $t_{1}, \mathrm{~s}$ \\
\hline 0.04 & 0.49 & 0.1 & 1.2 & 1.2 & 0.01 & 0,01 & 10 & 0.016 \\
\hline
\end{tabular}

of the main tube of the working and outlet chambers; $d_{1}, d_{2}$ - pipe diameters of the main tubes of the working and outlet chambers.

Linear programming optimisation technique [8] was used for the determination of optimal solution (Table 3 ). The optimization of technical-maintenance parameters of the rifle recoil imitation pneumatic drive was performed on the basis of the LP method (according to the Sobol points). The LP search is a determinate analogue of the random search. In the study [8], it is shown that compared to the random search, the LP search method may produce the same preciseness performing by $8-10$ times less tests.

Over 600 tests were performed and optimum sets of parameters maximizing the selected criterion (Table 3) were selected. As we can see from the table of sorted out criteria the optimal sets of parameters were got in tests No 383 and 448.

The final technical data of gun recoil imitation pneumatic drive are given in Table 4.

\section{Construction of the gun recoil simulation pneumodrive}

The synthesis of the gun recoil imitation pneumodrive was based on the results of optimisation. Pneu- modrive executing mechanism was mounted into the butt-stock of a training gun - the assault carabine AK$47 \mathrm{~S}$. The results of the measurement of acceleration, velocity and displacement performed in a single shot and four shot serial modes are presented in Fig. 7. It can be noted that the acceleration transducer was mounted on the butt-stock (measurements on the real AK-47S gun were performed directly on the lock). Comparison of the results proves high quality of the recoil process simulation both in terms of energy and pulse duration.

It should be stressed that the developed recoil simulation pneumatic drive is universal by its technical - operation properties and may be used in pneumatic guns of other type, as e.g. M-14, M-16 etc.

A laser rifleman trainer with the complete single shot and serial shots simulation LT- 2 has been employing a training gun. The scheme of this trainer is shown in Figs 8,9.

Single shots and serial shots in the trainer LT-2 are being simulated by means of infrared beams. Having pressed the gun trigger a laser beam is radiated according the command of the control block. Simultaneously the control block activates systems of sound simulation and compressed air supply. Therefore every shot is accompanied by the gun butt-stock recoil to the rifleman's shoulder and the rifleman gets a complete image of battle shooting. 


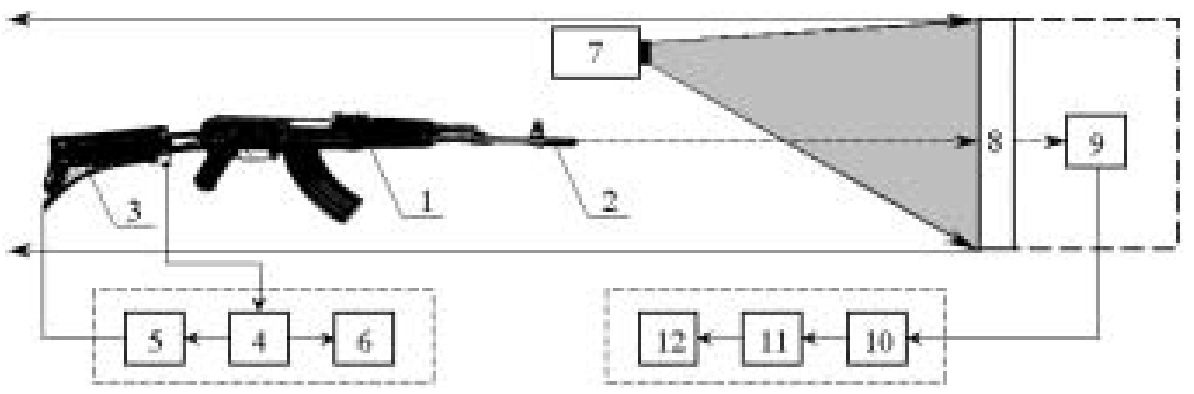

Fig. 8. The functional scheme of Laser riflemen trainer LT-2: 1 - training gun, 2 - infrared laser, 3 - pneumatic recoil simulation mechanism, 4 - control of laser, air and sound systems, 5 - compressed air supply system, 6 - shot sound simulation system, 7 - video projector, 8 - target screen, 9 - video camera, 10 - PC (data processing system), 11 - monitor, 12 - printer.

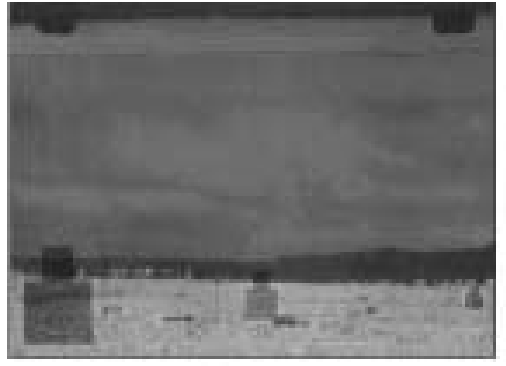

a

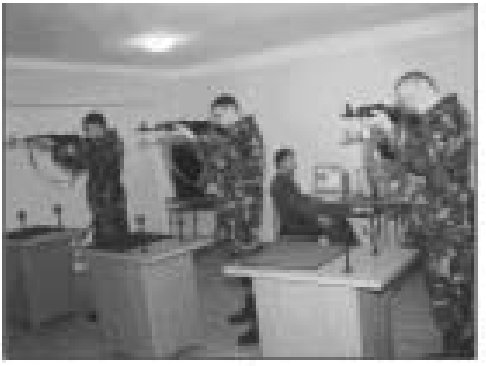

b

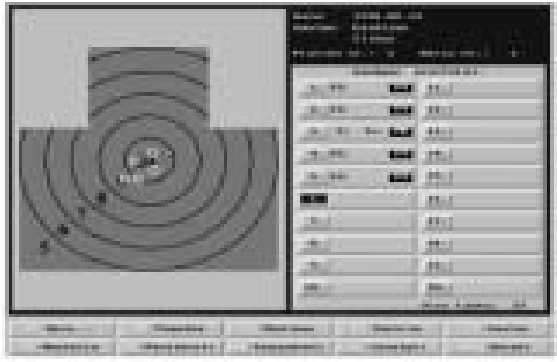

c

Fig. 9. Laser riflemen trainer LT-2: a - multimedia target view on the screen; b- fire line and working place of instructor; c- information on monitor.

\section{Conclusions}

The laser simulator is an effective aid for training the personnel of the defence system and sportsmen. Besides the mechnical recoil simulation the system comprises a system for transmitting infrared rays, a video receiving system and a computer system for data processing.

A dynamical and mathematical model for the system "Weapon - rifleman" was developed and investigated to determine the data, which is necessary for the dynamic synthesis of recoil simulation mechanisms. Interaction between a rifleman and a weapon in the single-shot mode and the serial shots mode was investigated theoretically and experimentally, as well as their psychological impact on a rifleman, which has to be reproduced in the course of shot simulation.

It was determined that two-side operation pneumatic pulse drives with forced control of operating conditions are the best to simulate recoil of small arms. Dynamic synthesis of a pneumatic drive was accomplished and its parameters were optimised. System parameters, which enable to assure 65-75 per cent of the energy of a recoil blow and the appropriate speed of operation in serial shot mode $(9.3 \mathrm{~Hz})$, were determined.
It can be noted that the synthesis of recoil imitation mechanism was far from being trivial due to the restrictions in space and weight. Moreover, the simulator must perform realistic recoil imitation in serial shot mode what brings the problem up to the critical limit of technical possibilities. Optimisation of system's parameters, numerical simulations and analysis lead to development of non-standard pneumatic drive with unique characteristics. Final tests made on the rifle simulator proved that the produced recoil effects correspond well with the ones in a real gun.

The structural synthesis of the laser simulator for riflemen with full simulation of single shots and series of shots was accomplished, which resulted in creation of a simulator that is accredited and successfully used in training riflemen for the national defence institutions in the Baltic countries.

\section{References}

[1] A. Fedaravičius, T.R. Toločka, A. Matukas and P. Jankauskas, Laser trainer for rifles with complete simulation of single shot and serials, Patents of the Republic of Lithuania (4203) (1997).

[2] A.M. Ashavskij, A.J. Volpert and V.C. Scheinbaum, Power impulse systems, Moscow: Maschinostroenije, 1978. 
[3] A. Fedaravičius, A. Matukas and R. Siurys, Investigation of the system Shot-rifle, Proceedings of Conference Mechanica-97. Kaunas, Lithuania, 1997, 213-223.

[4] E.B. Gerc and G.V. Kreinin, Design of pneumodrives, Maschinostroenije, Moscow, 1967.

[5] V.F. Gorbunov, V.J. Baburov and J.A. Zchartovskij, Handheld pneumo hammers, Maschinostroenije, Moscow, 1967.

[6] W.F. Ullrich, An innovative solution for infantry weapons trai- ning, Modern Simulation \& Training - The International Training Journal, Monch Publishing 2 (1999), 20-24.

[7] Industrial partners for Finish defence. Military Technology, Monch Publishing XXII (1998), 26-27.

[8] R.B. Statnikov, Application of LP meshes for the seek of optimal solutions in machine design problems, Mechanica maschin, Moscow, 1977. 

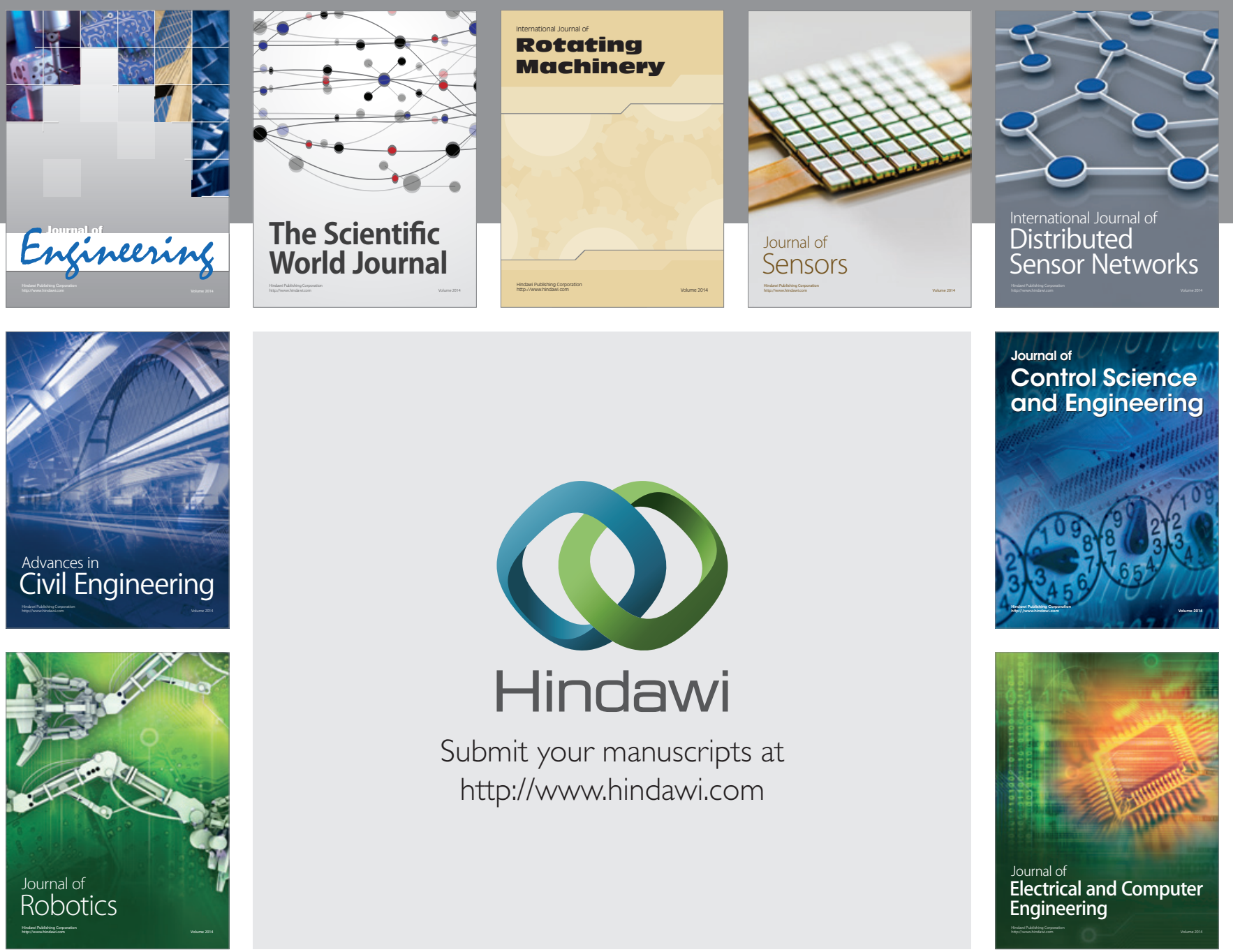

Submit your manuscripts at

http://www.hindawi.com
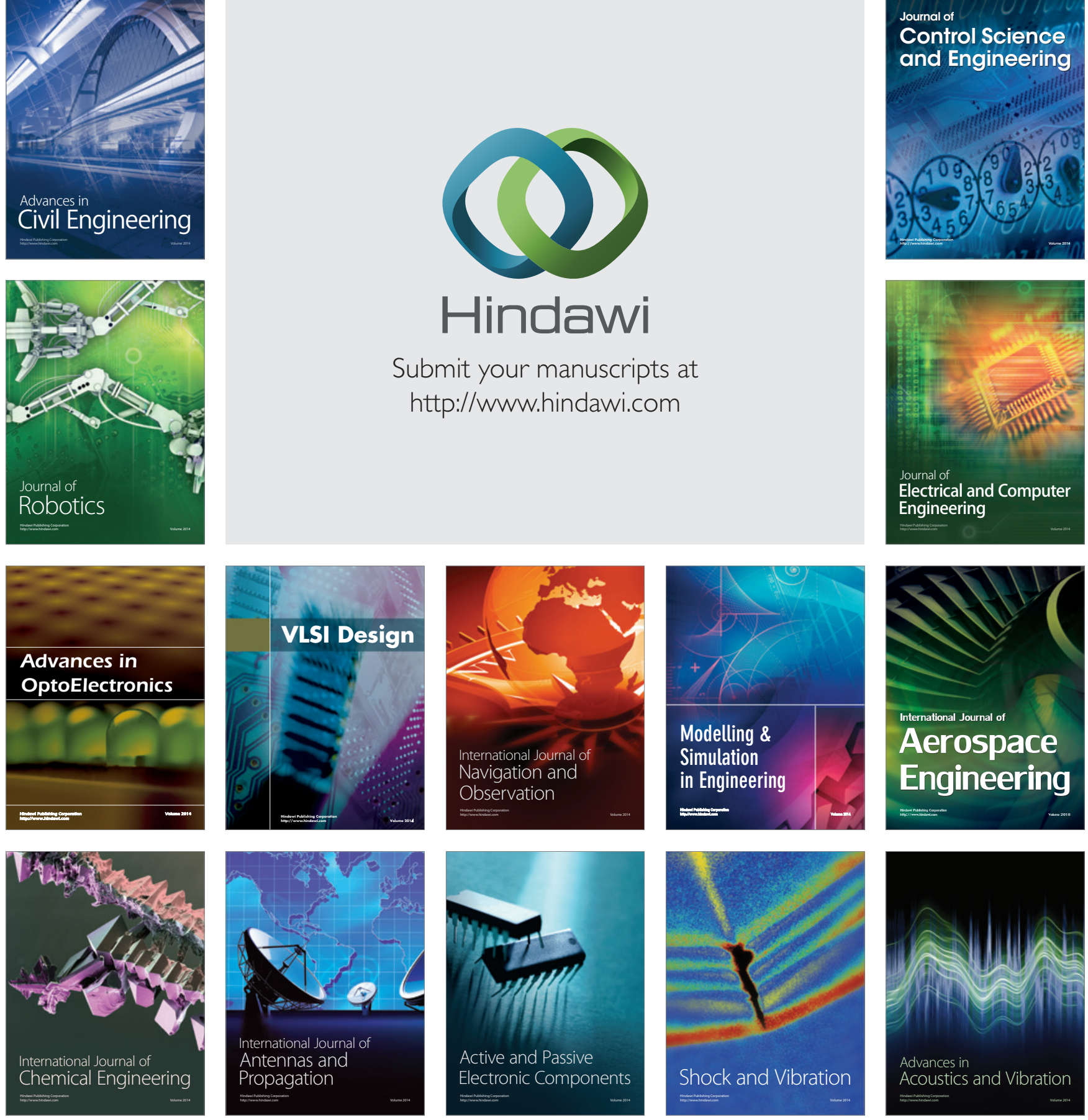